ter, and I beg you will excuse me for not having rendered my ysms of cough have ceased which will usually be after a very thanks to you before, as I have been prevented by very sad few hours.

private occurrences:

"Your different publications have interested me very much. In regard to the modern way of doctors concerning serumtherapy, I am thoroughly skeptical. Perhaps diphtheria has, for some time been your field; in regard to leprosy, we hardly could talk of such, as long as the culture of the lepra-bacillus has not been made. Those experiments made in Colombia (with Carrasquilla serum) appear to be very naive. I neither believe in nor trust them.

"You mention a proposition made by Dr. Goldschmidt, regarding a leper congress. That gentleman is known to me by name and by many publications. Although $I$ have not had the same experiences of therapeutics as those which Dr. Gold schmidt has published, I feel with regard to a congress that a real motive is wanting. The increasing danger of leprosy is well known. The Culture States, in their administrations take due regard of hygiene and protect themselves, and those States which do not do so, can or will not, and they do not understand the affair. Particular progress in our knowledge of leprosy and its treatment has, in the last years, not been made. Therefore, what are we going to do with a special congress? He who in this matter wants to talk about it, finds ample opportunity in the general congresses (Interior Medical Dermatologic Hygiene, or the International Congresses).

"I am just about undertaking a journey to Europe for study's sake, and intend to visit the leper hospital in Bergen. I would be highly interested to learn how much knowledge they have there in regard to lepra.

"While in this way answering some of the points of your letter, which has greatly interested me, I greet you and sign myself always your devoted friend,

Wm. Havelburg,"

\title{
A Cure for Whooping Cough.
}

Gainesville, Fla., July 16, 1896.

To the Editor:-In Keating's Cyclopedia of the Diseases of Children, the assertion is made that one-fourth of the infant mortality of London is caused from whooping cough, and from a study of the vital statistics as published in Public Health Reports issued by Supervising Surgeon-General Marine Hospital-Service I believe that the same ratio will hold good in many other cities. Having for a number of years used, with such happy results in this affection, a combination of old and approved remedies, I feel it to be my duty to publish the formula, feeling assured that almost any case can be cured in a week if the remedy be properiy used. Where the doctor can not supervise the administration of the medicine and thinks it not advisable to push the drugs to their physiologic effects the length of time necessary for a cure may be longer than a week, but the distressing paroxysms and dangers to life will have been quickly overcome.

This is the formula as I usually write it:

B. Tinct. belladonnæ . . . . . . 3iv to $3 \mathrm{vi}$ Phenacetin

Spirits frumenti .

Fl. ext. castaneæ (chestat leaves) . q. s. ad そvi

When one member of a family has developed the disease others who have been exposed can be prevented from developing any unpleasant symptoms by administering a few doses of the remedy.

R. A. Lancaster, M.D.

Ex-President Florida Medical Association.

\section{Typhoid Secondary Infection.}

WoodHuld, ILx., July 20, 1896.

To the Editor:-It was with considerable pleasure and satisfaction that I read the decision of the court of appeals of Colorado, Jones vs. Vroom, reported in our Jounnal, July 18, page 169. The reason it is interesting to me is that $I$ have a case pending, to come in the October term of court, where I have been sued for the loss of an eye from typhoid fever. My case was one of four cases that got their contagion in the same locality. Three different physicians treated the four cases. They were all extremely bad cases and they all died except this one case which lived, but has lost the sight of one eye from sloughing of the cornea. The case you reported appears to be very similar to mine, except the fact that they promised to provide a specialist and did not, while I simply did the best I could, never claiming to be a specialist. If you know of a record of any similar cases to the one you reported, or mine, and could advise me where to find the record, it might do me some good in my coming trial. My case is on the streets, fat and apparently well, but blind in one eye.
Respectfully,
W. S. McClanahan, M.D.

\section{The Business Committee.}

\section{Chicago, July 15, 1896.}

To the Editor:-I wish to call the attention of the members of the Association to a recommendation made at the last meeting by the Business Committee. The recommendation was not presented to the Association until the last session and was then, through a misapprehension I am sure, laid on the table. The belief that those who voted to lay the resolution on the table, would have voted to adopt it had they understood its provisions; and the belief that it is much easier to consider a proposition of this kind between meetings; than it is in the hurry of a session is my excuse for presenting it now. The recommendation was as follows: (See Journal May 16, 1896. Page 988).

"Resolved, That there be made an Executive Council of five, consisting of the three officers of the Executive Committee, and two members chosen by election. Of this Council of five, one must belong to the Section on Practice of Medicine and one to the Section on Surgery and Anatomy. To this Executive Council shall be delegated all the duties of the Executive Committee, during the intervals between its meetings."

The resolution is perhaps a little ambiguous, but the intention is very simple. It only gives permission to the Executive Committee to delegate their regular duties to a smaller committee of their own number, during the intervals between the meetings. It is impracticable for the whole committee to meet, but a sub-committee of five could meet and would be of great service in preparing for the annual meetings, and in attending to such matM. Sig. : Shake well.

Dose: From 10 drops for a ane-year-old to teaspoonful for ten-year-old child, every to six hours.

I am inclined to think that the substitution of atropiæ sulphate for the tinct. belladomma would be a more elegant prescription, but I have had wach good results from the formula as written above that I have had no occasion to ehange it.

This remedy should be given every two hours or oftener until the flushed face or dilated pupils show that the physiologic effects of the belladonma thas been obtained, then the dose can be lessened or the ïnterval between doses lengthened, but the effects must not be allowed to die out until the parox-

ters as would naturally come before them. No new powers or duties are delegated to this committee. They only act upon such questions between the annual meetings as come under the jurisdiction of the Business or Executive Committee during those meetings. Those being questions that do not particularly belong to any other officer or committee, it would be a decided gain to have some one with proper authority to consider and act upon them at any and all times. The ambiguity in the resolution as presented from the Executive Committee is in the first sentence. Had that been something like this, the resolution would probably not have met with opposition: 